УДК 681.51: 65.011.56

DOI: $10.18524 / 2413-9998 / 2020.2(45) .201486$

\begin{abstract}
А. В. Церковна, старший викладач кафедри менеджменту та інновацій Одеський національний університет імені I. I. Мечникова, Французький бульвар, 24/26, м. Одеса, 65058, Україна e-mail: timeoutproduct.ua@ukr.net

К. С. Карелова, студентка 4 курсу спеціальності «Менеджмент» Одеський національний університет імені I. I. Мечникова, Французький бульвар, 24/26, м. Одеса, 65058, Україна e-mail: karelovaa23@gmail.com
\end{abstract}

\title{
ВПЛИВ ЦИФРОВІЗАЦЇ̈ НА РОЗВИТОК МАЛОГО І СЕРЕДНЬОГО БІЗНЕСУ В УКРАЇНI
}

Стаття присвячена дослідженню сучасних тенденцій i можливостей цифровізації малого і середнього бізнесу. У процесі аналізу позначена роль представників малого та середнього бізнесу в забезпеченні економічного зростання і підтримці стабільності в країні. Також окрему увагу приділено перевагам суб’ єктів МСБ в порівнянні з великими підприємствами і корпораціями, які полягають у гнучкості, простоті бізнес-процесів, готовності приймати ризик і високої мотивації. Ці обставини обумовлюють той факт, що сучасні цифрові технології перетворилися в ендогенний фактор ефективності розвитку суб'єктів малого і середнього бізнесу. Особливий акцент зроблений на нових бізнес-моделях МСБ в епоху цифровізації і їх характерні риси.

Ключові слова: цифровізація; малий та середній бізнес; економіка; інноваційний простір; інформаційна система; цифрові технології.

Постановка проблеми у загальному вигляді. Цифровізація це повсюдне впровадження цифрових технологій в різні сфери життя: промисловість, економіку, освіту, культуру, обслуговування і т.п.

Це явище викликане стрімким розвитком інформаційних технологій, мікроелектроніки та комунікацій в більшості країн світу. Цифровізація - це глобальний процес, який з кожним днем все більше підпорядковує планету.

Стрімкий розвиток цифрової економіки призвело до того, що сьогодні лідерів ринку визначає не багаторічна історія успіху, 
не вартість активів, не кількість патентів або доступ до капіталу, а здатність змінювати бізнес-модель на хвилі технологічної революції. Цифрові технології розвиваються з експоненційною швидкістю, та докорінно змінюючи суть бізнесу та кожну галузь [1].

Крім того, вони допомагають знайти джерела підвищення ефективності і можливості стійкого конкурентного розвитку підприємств. В той же час, проривні інновації вимагають змін в існуючих моделях управління, реформування комунікацій, технологій і організаційної структури підприємств на основі нових цінностей, пріоритетів і орієнтирів, заснованих на партнерстві, клієнтоорієнтованості, інноваційності та синергії [5].

Аналіз останніх досліджень та публікацій. Актуальним аспектам становлення цифрової економіки і трансформаційних процесів, які відбуваються в економічному просторі під їі впливом, значну увагу приділяють такі дослідники як: К. Фрімен, П. Друкер, Дж. Тис, К. Крістенсен, Г. Мінцберг, С. Гошал, Б. Мільнер, А. Бутник-Сіверський, І. Галиця, Н. Гончарова та ін.

Постановка завдання. Мета статті полягає у вивченні тенденцій i можливостей цифровізації малого i середнього бізнесу. Застосування новітніх цифрових технологій в бізнесі $\epsilon$ необхідною умовою для ефективного розвитку суб'єктів підприємництва. Зазначені обставини активізують розвиток малого і середнього бізнесу, що є одним 3 провідних секторів економіки, який визначає темпи економічного зростання, склад та якість валового національного продукту, а також має всі можливості гнучко реагувати на потреби ринку і мінливі умови господарювання.

Виклад основного матеріалу дослідження. П'ятірку країнлідерів за рівнем участі малого і середнього бізнесу в ВВП становлять Китай, ЄС, США, Індія і Росія. Малий і середній бізнес в Україні приносить 55 \% валового внутрішнього продукту в економіку країни.

Великі корпорації оперативні у впровадженні у своїй діяльності цифрових інновацій, але вплив цифрових технологій проявляється в малому і середньому бізнесі також. 
Сьогодні особливість діяльності сучасних малих і середніх підприємств полягає в тому, що цифрові технології перетворилися у внутрішній фактор ефективності їх розвитку. Це означає, що шанси виправдати очікування клієнтів, яких глобальний світ привчив швидко і зручно отримувати сучасні послуги у гігантів, тепер у всіх однакові. Наприклад, модель економіки спільної участі, якою керуються Aliexpres або Airbnb, збільшує конкуренцію і навіть витісняє з ринку провідні світові компанії. Хмарні технології дозволяють малому і середньому бізнесу зменшити витрати на інфраструктуру, тим самим прискорюючи комерційні процеси, didgital-маркетинг дає можливість налагоджувати ефективні взаємини з клієнтами, CRM-системи економити на персоналі.

Однак, на шляху цифровізації своєї діяльності малі i середні підприємства стикаються 3 певним каскадом проблем, пов'язаних з високими ставками оподаткування, несприятливим інвестиційним кліматом, обмеженістю доступу до джерел фінансування, збільшенням тиску державних органів. Також ключовою перешкодою для розвитку цифрових технологій в сегменті малого i середнього бізнесу $є$ питання безпеки i збереження даних [2].

Отже, з урахуванням вищевикладеного, можна стверджувати, що цифровізація малих і середніх підприємств має деякі особливості, які є як їх перевагами, так і недоліками, в порівнянні 3 великими формами організації бізнесу. Дослідження цих особливостей і пошук шляхів використання позитивних аспектів, які дозволять подолати вплив негативних сторін, дасть можливість підвищити рівень відцифровки діяльності малих підприємств i, отже, рівень інноваційності економіки країни в цілому, що і зумовило вибір теми даної статті.

Значний інтерес викликає дослідження американського вченого В. Баумоля, який протиставив рутинним інноваціям великих компаній, так звану «незалежну» цифровізацию, носіями якої є малі підприємства.

При цьому, на думку вченого, саме інновації малих суб'єктів господарювання відрізняються своєю радикальністю і новизною [3]. 
Так, за останні 10 років частка представників малого та середнього бізнесу, які використовують і продукують цифрові технології, збільшилася практично на $20 \%$.

В даному контексті, можна відзначити, що перспективи розвитку малого і середнього бізнесу в умовах цифровізації економіки, пов'язані з такими факторами:

- діяльністю на цифрових платформах (маркетплейсах), які забезпечують безпосередні комунікації між виробниками і споживачами;

- зменшенням трансакційних витрат при одночасному підвищенні продуктивності праці;

- глобальною присутністю завдяки виходу на електронні ринки і активізації глобальної гіперконкуренції;

- підвищенням споживчої цінності товарів і послуг внаслідок їх персоналізації;

- омніканальностью комунікацій з споживачами і покупцями;

- скороченням життєвого циклу інновацій та продуктів.

При цьому, необхідно звернути увагу на той факт, що нові можливості цифрової економіки, які відкриваються для малих і середніх підприємств, пов'язані з ростом ризиків і підвищеним рівнем невизначеності при прийнятті стратегічних рішень в результаті динамічних змін технологій і кон'юнктури ринків. Однак ці загрози незменшують прагнення підприємств апробувати нові цифрові можливості, і з року в рік малий і середній бізнес нарощує інвестиції в сучасні IT-рішення [4].

Так, згідно з даними IDC, загальносвітові IT витрати МСБ в 2019 р склали близько 602 млрд дол., що свідчить про зростання в 4,9\% у порівнянні з попереднім роком. Крім того, передбачається, що при середньорічному збільшенні за період з 2016 по 2021 року в розмірі 4,7\%, витрати компаній зі штатом менше 1000 співробітників на апаратне і програмне забезпечення, а також послуги (включаючи бізнес-послуги) досягнуть 684 млрд дол. [5].

16 лютого 2020 року аналітики IDC опублікували дослідження, в якому повідомили, що спалах коронавируса COVID-19 в Китаї не тільки підриває світову економіку, а й здатен сприятливо відбитися 
на розвитку ІКТ-галузі та відкриває нові бізнес-можливості для розробників інформаційно-комунікаційних технологій. Крім того, на думку фахівців, створюються нові можливості для компаній i сервісів, що пропонують співробітникам віддалену роботу. Змінюються підходи і в освіті: при масових захворюваннях люди будуть прагнути до дистанційної освіти і онлайн-курсів.

Можливості для розвитку бізнесу отримують розробники технологій для магазинів, де використовується мінімум персоналу або до того всі відсутня, а також інтернет-сервіси з доставки їжі і оператори зв'язку при будівництві 5G-мереж і запуску послуг на їх основі.

Є кілька заходів, які можуть поліпшити фінансову ситуацію малого і середнього бізнесу, але не всі компанії почали їх впроваджувати:

- реструктурувати і відкласти борги і позики від партнерів i фінансових інститутів.

- переглянути умови оплати оренди нерухомості, звернувшись з проханням про значну знижку або відстрочку.

- перевести якомога більше співробітників на спрощену систему оподаткування для зниження податкового навантаження.

Відносно цифровізації, то необхідно створювати платформи для онлайн продажів (e-commerce) і приймати інноваційні інтернет рішення, або перехід на роботу online. Потрібна зміна форматів адміністрування і продажів через інтернет, що дозволить скоротити витрати і підтримати виручку хоча б на мінімальному рівні.

Коротко розглянемо найбільш актуальні програми для підприємств МСБ, які рекомендують фахівці під час дії карантину в Україні:

1. Програми-організатори:

Trello - допомагає керувати проектами та вести план виходу контента.

Інструмент пропонує декілька сценаріїв для роботи і пояснює, як все настроїти. Trello допомагає оптимізувати роботу дизайнерів, маркетологов, менеджерів з продажу тощо.

Click-Up - більш функціональна програма для управління проектами. У платформи є такий самий функціонал, як і в Trello, 
але з’являється більше можливостей для аналізу проектів: гнучкі звіти, які команди можуть налаштувати для своїх потреб, більше варіантів сітьового графіку, є діаграма Ганта.

Click-Up також зручний для найму працівників, роботи фрілансерів, для розробки додатків, створення контенту, інвентаризації та у багатьох інших ситуаціях.

Інструмент також зручний для ведення фінансового обліку та CRM.

2. Програми для проведення нарад і вебінарів:

Skype для бізнесу. 3 ним можливі групові дзвінки до 250 чоловік і вебінари до 10000 учасників. Деякі особливості:

- програма працює в інтеграції з іншими офісними програмами в Windows;

- можна призначати зустрічі в Skype прямо з Word aбо OutLook;

- дозволяє розмовляти i показувати презентацію в кращій якості;

- можна проводити голосування між присутніми на зустрічі;

- можна записувати на відео всю або частину зустрічі;

- можливо встановлення тимчасових періодів для зберігання документів.

Zoom. Дуже простий інструмент, один 3 лідерів на ринку. Розпочата конференція легко синхронізується на всіх пристроях. Зручно робити нотатки в режимі онлайн. Можна проводити вебінари до 10000 учасників.

3. Сховища для зберігання даних:

Google Drive. У сховища є своя система електронних документів Docs, які дуже зручно редагувати в режимі онлайн разом з іншими співробітниками. Безкоштовно можна користуватися 15GB для зберігання файлів на хмарі. Якщо ви використовуєте платформу в компанії і потрібно більше пам'яті, то Google пропонує заплатити \$ 0,04 за GB i \$ 8 в місяць за кожного активного користувача.

DropBox. За 18 євро в місяць на одного користувача надається безлімітний простір для зберігання. Синхронізація документів швидше і безпечніше, ніж в Google Drive.

4. Програми для планування часу: 
Google Calendar. Це зручний онлайн-інструмент для планування. Можна додавати кілька календарів для себе особисто, різних груп і компанії в цілому. Зручно стежити, щоб не було накладок. Відмінно синхронізується з поштою Gmail.

Вищеперечислені програми не потребують великих витрат за користування, але допоможуть працівникам невеликих підприємств працювати онлайн, розробляти проекти, проводити конференції, i, як результат, пережити вимушений карантин.

Як свідчать статистичні дані найбільш активну цифрову діяльність ведуть представники МСБ в США (витрати 186 млрд дол.), на другому місці знаходиться Китай (56 млрд дол.), замикає трійку лідерів Німеччина (37 млрд дол.) [5].

Для порівняння серед країн Центральної і Східної Свропи, лідерами за рівнем використання цифрових технологій в сегменті малого і середнього бізнесу є Чехія, Греція, Польща і Словаччина, де в середньому $75 \%$ підприємств мають хоча б одну цифрову опцію [5].

У Греції, зокрема, високі показники пояснюються тим, що цифровізація МСБ є обов'язковою згідно з вимогами місцевого законодавства.

В цілому можна відзначити, що представники малого i середнього бізнесу для забезпечення конкурентних позицій і майбутньої цифровізації своєї діяльності вирішують на сьогоднішній день такі стратегічні завдання:

- по-перше, установлення більш тісних відносини 3 постачальниками і замовниками;

- по-друге, підвищення рівня власної операційної ефективності;

- по-третє, підвищення конкурентоспроможності продукції, що випускається.

Очевидно, що виконання всіх цих трьох завдань неможливо без інтеграції інформаційних систем і цифрових технологій у виробничу сферу (табл. 1). 
Таблиця 1

\section{Групи бізнес-процесів МСБ і цифрові технології (системи, інструменти, програми) для їх трансформації}

\begin{tabular}{|l|l|}
\hline \multicolumn{1}{|c|}{ Групи бізнес-процесів } & \multicolumn{1}{|c|}{$\begin{array}{c}\text { Цифрові інструменти (системи, продукти, } \\
\text { програмні рішення) }\end{array}$} \\
\hline $\begin{array}{l}\text { Взаємодія з } \\
\text { постачальниками }\end{array}$ & Системи SCM (Supply Chain Management) \\
\hline $\begin{array}{l}\text { Взаємодія з замовниками } \\
\text { (споживачами) }\end{array}$ & $\begin{array}{l}\text { Системи CRM (Customer Relationships } \\
\text { Management) }\end{array}$ \\
\hline $\begin{array}{l}\text { Управління ресурсами } \\
\text { ERP (Enterprise Resources Planning) }\end{array}$ \\
\hline $\begin{array}{l}\text { Управління бізнес- } \\
\text { процесами }\end{array}$ & BPM-системи (Business process management) \\
\hline $\begin{array}{l}\text { Управління аналітичної } \\
\text { складової (аналіз даних) }\end{array}$ & $\begin{array}{l}\text { Технології Big Data, Data mining, } \\
\text { хмарні обчислення, Google Analytics, iн. }\end{array}$ \\
\hline $\begin{array}{l}\text { Маркетингова-діяльність, в } \\
\text { т.ч .: цифрові інструменти } \\
\text { інтернет-маркетингу }\end{array}$ & $\begin{array}{l}\text { Використання інструментів Google Analytics, } \\
\text { Google Adwords; SEO, SMM }\end{array}$ \\
\hline
\end{tabular}

Джерело: сформовано авторами на основі $[4 ; 5 ; 6]$.

Стосовно України, Кабінет міністрів затвердив 3 доопрацюванням Стратегію розвитку цифрової економіки України до 2021 року. Амбітна мета - досягти до 2021 року зростання на $5 \%$ ВВП завдяки розвитку цифрової економіки. За даними дослідження «Цикли зрілості цифровий трансформації» компанії Enterprise Strategy Group, проведеного на замовлення компанії Dell EMC, 96 \% компаній, де пройшла цифрова трансформація, на наступний рік майже вдвічі перевиконали свої плани по доходах. Втім, якщо ми говоримо про розвиток нашої країни не тільки як торговця сировинними ресурсами, то інтеграція вітчизняних підприємств у світову економіку без цифрових технологій вже неможлива.

Висновки та пропозиції. Таким чином, підбиваючи підсумки проведеного дослідження, можна зробити наступні висновки. 
Цифровізація малого і середнього бізнесу в будь-який країні світу є стратегічно важливим рішенням, яке часто порівнюють 3 революційними перетвореннями, оскільки ефект від їх реалізації $\epsilon$ дуже значним. Бізнес, який працює на основі сучасних інформаційно-комунікаційних технологій, це ефективний i конкурентоспроможний бізнес, який готовий до інтеграційних процесів і виходу на міжнародні ринки. Найбільша цифровізація підприємств МСБ спостерігається в США, КНР, Німеччини. Найпопулярнішими сферами цифровізації для малого i середнього бізнесу $є$ інтернет-маркетинг, охорона здоров'я, мобільні технології, телекомунікації, програмне забезпечення та розробки для промисловості.

Сучасні представники малого і середнього бізнесу мають всі можливості і передумови для активного використання передових інформаційно-комунікаційні технології в своїй діяльності, завдяки більш простим бізнес-процесів, гнучкості, раціональну структуру витрат, прямому контакту з клієнтами, готовність до ризику і високої мотивації. Однак слід брати до уваги і ряд обмежень відцифровки суб'єктів МСБ, які пов'язані зі складнощами залучення фінансових ресурсів, обмеженістю диверсифікації i масштабного виробництва, низьким професійним рівнем керівництва по порівняно з великими підприємствами.

\section{Список використаної літератури}

1. Варнакова Г. Ф., Фадеева А. О. Малый бизнес на пути цифровизации экономики. Аллея науки. 2019. № 1 (28). С. 825-828.

2. Грибанов Ю. И., Репин Н. В. Институциональные эффекты и последствия цифровизации бизнеса. Экономика и предпринимательство. 2017. № 11 (88). C. $1130-1139$.

3. Коробейникова Е. В. Управление продажами на предприятии в условиях цифровизации бизнеса. Экономика и предпринимательство. 2018. №6 (95). C. 637-641.

4. Лебедев В. А., Лебедева Е.И. О цифровой экономике... и не только. Научные исследования и разработки. Экономика фирмы. 2018. Т. 7. № 4. С. 5-11.

5. Juhani et al. Mapping Business Transformation in Digital Landscape: A Prescriptive Maturity Model for Small Enterprises. Communications in computer and information science. 2018. № 907. P. 101-116. URL: https://www.springerprofessional.de/en/ mapping-business-transformation-in-digital-landscape-a-prescript/16029438 (дата 
звернення: 12.03.2020).

6. Flipping the switch on rural digital entrepreneurship: hearing before the Committee on Small Business, United States House of Representatives, One Hundred Sixteenth Congress, first session, hearing held March 13, 2019. URL: https://searchworks. stanford.edu/view/13284103 (дата звернення: 15.03.2020).

7. Digital transformation scoreboard 2018: EU businesses go digital: opportunities, outcomes and uptake. Luxembourg: Publications Office of the European Union. 2018. URL: https:/ec.europa.eu/growth/tools-databases/dem/monitor/scoreboard (дата звернення: 20.03.2020).

8. ABE Level 3 Award in Digital Marketing Essentials for Small Businesses.: Your road to success. New Malden: Association of Business Executives. 2017. URL: https:// www.abeuk.com/sites/default/files/files/ABE\%20Level\%203\%20Award\%20 in $\% 20$ Digital $\% 20$ Marketing\%20Essentials $\% 20$ for $\% 20$ Small\%20Businesses.pdf (дата звернення: 20.03.2020).

9. Richmond W., Scott R., Clinton L. The «digital divide» for rural small businesses. Journal of research in marketing and entrepreneurship. 2017. Volume 19. Issue 2: 94-104. URL: https://www.emerald.com/insight/content/doi/10.1108/JRME-022017-0006/full/html?skip Tracking=true (дата звернення: 25.03.2020).

\title{
А. В. Церковна,
}

Стаття надійшла 05.04.2020 p.

старший преподаватель кафедры менеджмента и инноваций, Одесский национальный университет имени И. И. Мечникова Французский бульвар, 24/26, г. Одесса, 65058, Украина e-mail: timeoutproduct.ua@ukr.net

\author{
К. С. Карелова, \\ студентка 4 курсу специальности «Менеджмент» \\ Одесский национальный университет имени И. И. Мечникова \\ Французский бульвар, 24/26, г. Одесса, 65058, Украина \\ e-mail: karelovaa23@gmail.com
}

\section{ВЛИЯНИЕ ЦИФРОВИЗАЦИИ НА РАЗВИТИЕ МАЛОГО И СРЕДНЕГО БИЗНЕСА В УКРАИНЕ}

Статья посвящена исследованию современных тенденций и возможностей цифровизации малого и среднего бизнеса. В процессе анализа обозначена роль представителей малого и среднего бизнеса в обеспечении экономического роста и поддержании стабильности в стране. Также особое внимание уделено преимуществам субъектов МСБ по сравнению с крупными предприятиями и корпорациями, которые заключаются в гибкости, простоте бизнес-процессов, готовности принимать риск и высокой мотивации. Эти обстоятельства обуславливают тот факт, что современные цифровые технологии превратились в эндогенный фактор эффективности развития субъектов малого и среднего бизнеса. 
Особый акцент сделан на новых бизнес-моделях МСБ в эпоху цифровизации и их характерные черты.

Ключевые слова: цифровизация; малый и средний бизнес; экономика; инновационное пространство; информационная система; цифровые технологии.
A. V. Tserkovna,
Senior Lecturer
of Economics and Management Department
Odessa I. I. Mechnikov National University
24/26 Frantsuzkyi bulvar, Odessa, 65058, Ukraine
e-mail: timeoutproduct.ua@ukr.net

\author{
K. S. Karelova, \\ 4th year student of the specialty "Management" \\ Odessa I. I. Mechnikov National University \\ 24/26 Frantsuzkyi bulvar, Odessa, 65058, Ukraine \\ e-mail: karelovaa23@gmail.com
}

\section{IMPACT OF DIGITALIZATION ON THE DEVELOPMENT OF SMALL AND MIDDLE BUSINESS IN UKRAINE}

The article is dedicated to the achievement of current trends and capabilities of digitalization of small and medium business. In the process of analysis, the role of representatives of the small and medium business in the secured economic and financial stability and stability in the country is designated. Also, I see respect for the advancement of SMB sub-sectors in large numbers of great enterprises and corporations, the same way as nooks, the simplicity of business processes, the willingness to accept the price and the highest motivation. For your convenience, consider the fact that right now digital technologies have transformed into an endogenous factor of efficiency in developing sub-projects of small and medium-sized businesses. A special emphasis is placed on new business models of SMBs in the era of digitalization and characterization of rice.

Key words: digitalization; small and medium business; economy; innovative space; information system; digital technology.

\section{References}

1. Varnakova, G. F. \& Fadeeva, A. O. (2019). Malyi biznes na puti tsifrovizatsii ekonomiki [Small business on the path of digitalization of the economy]. Alleia nauki. - Alley of Science. Vol. 1 (28). Pp. 825-828. [in Russian].

2. Gribanov, Yu. I. \& Repin, N. V. (2017). Institutsionalnye effekty i posledstviia tscifrovizatsii biznesa [Institutional effects and consequences of business digitalization]. Ekonomika i predprinimatelstvo. - Economics and entrepreneurship. Vol. 11 
(88). Pp. 1130-1139. [in Russian].

3. Korobeinikova, E. V. (2018). Upravlenie prodazhami na predpriiatii v usloviiakh tsifrovizatsii biznesa [Sales management in an enterprise in the context of business digitalization]. Ekonomika i predprinimatelstvo. - Economics and entrepreneurship. Vol. 6 (95), Pp. 637-641. [in Russian].

4. Lebedev, V. A. \& Lebedeva, E. I. (2018). O tsifrovoi ekonomike... i ne tolko [About the digital economy ... and more]. Nauchnye issledovaniia i razrabotki. Ekonomika firmy. - Scientific research and development. The economy of the company. Vol. 4. Pp. 5-11. [in Russian].

5. Naskali, Juhani (2018). Mapping Business Transformation in Digital Landscape: A Prescriptive Maturity Model for Small Enterprises. Communications in computer and information science. Vol. 907, Pp. 101-116. Retrieved from https://www. springerprofessional.de/en/mapping-business-transformation-in-digital-landscapea-prescript/16029438

6. Flipping the switch on rural digital entrepreneurship: hearing before the Small Business Committee, United States House of Representatives, One Hundred Sixth Congress, first session, hearing held March 13, 2019. Retrieved from https://searchworks.stanford.edu/view/13284103.

7. Digital transformation scoreboard 2018: EU businesses go digital: opportunities, outcomes and uptake. Luxembourg: Publications Office of the European Union. (2018). Retrieved from https://ec.europa.eu/growth/tools-databases/dem/monitor/ scoreboard

8. ABE Level 3 Award in Digital Marketing Essentials for Small Businesses: Your Road to Success. New Malden: Association of Business Executives. 2017. Retrieved from https://www.abeuk.com/sites/default/files/files/ABE\%20Level\%203\%20 Award\%20in\%20Digital\%20Marketing\%20Essentials\%20for\%20Small\%20Businesses.pdf

9. Richmond, W., Scott, R. \& Clinton, L. (2017). The "digital divide" for rural small businesses. Journal of Research in Marketing and Entrepreneurship. Vol. 19 (2). Pp. 94-104. Retrieved from https://www.emerald.com/insight/content/doi/10.1108/ JRME-02-2017-0006/full/html?skipTracking=true 